\title{
BODY MASS INDEX AND HEEL PAIN- A HOSPITAL-BASED STUDY
}

\author{
Debanga Sarma Barua1, Manasjyoti Das², Shantanu Lahkar ${ }^{3}$
}

${ }^{1}$ Assistant Professor, Department of Orthopaedics, Assam Medical College, Dibrugarh, Assam, India.

2Postgraduate Student, Department of Orthopaedics, Assam Medical College, Dibrugarh, Assam, India.

${ }^{3}$ Ex-Professor and HOD, Department of Orthopaedics, Assam Medical College, Dibrugarh, Assam, India.

\section{ABSTRACT}

\section{BACKGROUND}

Heel pain is one of the fastest growing problems in the community. Overweight or obesity is suggested as a key factor associated with heel pain.

\section{MATERIALS AND METHODS}

A prospective observational study consisting of 194 patients with chief complaints of heel pain were included in the study conducted from $1^{\text {st } J u l y ~} 2006$ to $31^{\text {st }}$ November 2007. The height and weight measures were used to calculate the participant's BMI (weight in kg divided by the square of height in metres). Stratification of BMI using the World Health Organization (WHO) International classification for BMI: underweight $\left(<18.50 \mathrm{~kg} / \mathrm{m}^{2}\right)$, normal $\left(18.50-24.99 \mathrm{~kg} / \mathrm{m}^{2}\right)$, overweight $\left(25.00-29.99 \mathrm{~kg} / \mathrm{m}^{2}\right)$ and obese $\left(>30.00 \mathrm{~kg} / \mathrm{m}^{2}\right)$ was done. Standardised self-reported heel pain questionnaire, clinical examination and standard weight bearing antero-posterior and lateral radiographs were obtained in all cases of heel pain.

\section{RESULTS}

Out of a total of 16,480 patients attending Orthopaedics OPD, 194 cases with heel pain were included in the study (1.18\%). 43\% cases had a BMI of $>25$. Amongst the total sample size, 111 patients were male and 83 were female. 41 male patients (37\%) and 42 female patients $(51 \%)$ had BMI $>25$. No cases were reported in the first two decades. The youngest patient was aged 20 years and the oldest was 79 years old. Maximum patients belonged to the fourth decade. Medial aspect of heel (72\%) was most commonly affected.

\section{CONCLUSION}

This is probably the first study of its kind in the North Eastern Region of the country demonstrating that high BMI is a likely risk factor for the development of heel pain, particularly in the females.

\section{KEY WORDS}

Body Mass Index, Heel Pain, Obesity.

HOW TO CITE THIS ARTICLE: Barua DS, Das M, Lahkar S. Body mass index and heel pain- a hospital-based study. J. Evolution Med. Dent. Sci. 2018;7(29):3317-3320, DOI: 10.14260/jemds/2018/747

\section{BACKGROUND}

In 1922 Steill[1] stated- "Painful heel appears to be a condition which is seldom efficiently treated for the simple reason that the causation is not exactly diagnosed." Lapidus and Guidotti[2] in 1965 stated that the name of painful heel is used deliberately in preference to any other more precise aetiological diagnosis, since the cause of this definite clinical entity still remains unknown. Now even after 50 years, the cause of heel pain still remains a diagnostic dilemma.

The foot is a complex structure of 28 bones, 33 joints, 57 articulating surfaces, 112 ligaments and 20 muscles. Enormous amount of forces act upon the foot during walking and running. The heel can absorb $110 \%$ of the body's weight during walking and $200 \%$ of the body's weight during running.[3]

Heel pain is one of the fastest growing problems in the community. It is a common problem in adults that may cause significant discomfort and disability. Various soft tissue, osseous and systemic disorders can cause heel pain such as

'Financial or Other Competing Interest': None.

Submission 04-06-2018, Peer Review 26-06-2018,

Acceptance 04-07-2018, Published 16-07-2018.

Corresponding Author:

Manasjyoti Das,

Department of Orthopaedics,

Assam Medical College, Dibrugarh-786002,

Assam, India.

E-mail: manasjyotidr@gmail.com

DOI: $10.14260 /$ jemds $/ 2018 / 747$
Achilles tendonitis, fat pad trophy, heel contusion, plantar fascia rupture, tarsal tunnel syndrome, abductor digiti quinti nerve entrapment, Sever's disease, calcaneal stress fracture, osteomyelitis etc.[4]

Overweight or obesity may be a key factor associated with heel pain.[5] Both heel pain and obesity peak around middle age, predominantly in women.[6] There are three hypotheses relating to heel pain and BMI. Firstly, heel pain develops first and causes a decrease in activity levels resulting in weight gain.[7] Second, a high Body Mass Index (BMI) or obesity precedes foot pain that causes increase in load on the joints and structures of the feet resulting in heel pain. ${ }^{[8,9]} \mathrm{A}$ third and more recent hypothesis suggests that there may be a metabolic element with regard to body composition, generally increased adipose tissue and foot pain. ${ }^{[10,11]}$

In this prospective observational study, we have tried to find out the incidence of obesity in heel pain patients and also some other factors such as age, sex, site of distribution in the heel etc. are dealt here.

\section{MATERIALS AND METHODS Study Sample and Study Design}

194 patients attending the Outpatient Department of Orthopaedic Surgery, Assam Medical College and Hospital, Dibrugarh with the chief complains of heel pain were included in the study. This prospective observational study was conducted from $1^{\text {st }}$ July 2006 to $31^{\text {st }}$ November 2007, a 
duration of seventeen months. All cases presenting with painful heel during this period were included. Acute heel pain due to trauma or acute infection were excluded. Also, any other pathological condition of the heel such as tumours were excluded. Foot deformities such as cavus foot, heel valgus and flat foot were excluded.

\section{Assessment of Demographic and Clinical Characteristics}

Age was recorded in whole years depending on the participant's age on the day of their first visit. The patient's history, clinical examination was systematically recorded which gave a clue to those patients who required investigations. Height was measured in $\mathrm{cm}$ (to the nearest 0.1 $\mathrm{cm}$ ) in a standing position and barefoot using a wall-mounted stadiometer and then was converted to metres. Weight was measured in $\mathrm{kg}$ (to the nearest $0.1 \mathrm{~kg}$ ) by electronic scales with shoes removed.

\section{Body Mass Index (Quetelet's Index)}

The height and weight measures were used to calculate the participant's BMI (weight in $\mathrm{kg}$ divided by the square of height in metres) (BMI= Weight in $\mathrm{kg} /$ Height in $\mathrm{m}^{2}$ ). Stratification of BMI was made using the World Health Organization (WHO) International classification for BMI: underweight $(<18.50 \mathrm{~kg} / \mathrm{m} 2)$, normal (18.50 -- 24.99 $\mathrm{kg} / \mathrm{m} 2)$, overweight $(25.00-29.99 \mathrm{~kg} / \mathrm{m} 2)$ and obese $(>30.00$ $\mathrm{kg} / \mathrm{m} 2$ ).[12] However, BMI may not correspond to the same degree of fatness in different population due, in part, to differences in body proportion.

\section{Heel Pain}

A standardised self-reported heel pain questionnaire was used to capture information regarding the duration, onset, characteristic and factors related to the pain symptoms. The questionnaire excluded other associated systemic and local causes such as trauma and infection. Clinical examination was done to reinforce the findings of the questionnaire and to rule out any other pathologies and foot deformity. Also, standard weight bearing antero-posterior, lateral and axial radiographs were obtained in all cases of heel pain.

\section{RESULTS}

A total of 16,480 patients attended the Orthopaedics OPD of $\mathrm{AMCH}$, out of which 194 cases with heel pain were included in the study comprising an incidence of about $1.18 \%$ (Figure1). $43 \%$ (84 cases) of the total cases of heel pain had a BMI (Body Mass Index) of $>25$, i.e. overweight patients (Figure-2). Out of the 194 included heel pain patients, 111 patients were male and 83 were female. 41 male patients (37\%) and 42 female patients $(51 \%)$ had BMI $>25$. Thus, BMI may be more strongly related as a risk factor in the female patients than the male patients (Table-1).

There were no cases in the age group of 0 - 19 years. The youngest patient in the study was aged 20 years and the oldest was 79 years old. Maximum patients belonged to fourth decade (Table-2).

The site of heel pain was most commonly found in the medial aspect of heel (72\%) followed by pain in the sole $(13 \%)$ and pain in the post part of the heel $(12 \%)$. Diffuse heel pain involving medial, lateral, posterior and sole of the heel comprises $3 \%$ of heel pain (Figure-3).

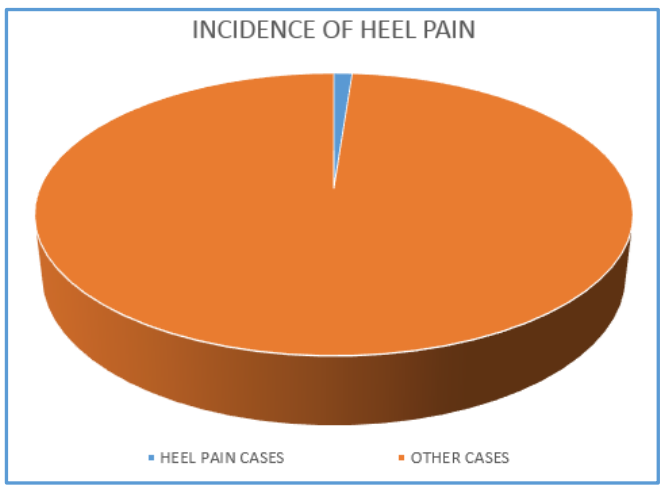

Figure 1. Incidence of Heel Pain amongst patients attending Orthopaedics OPD

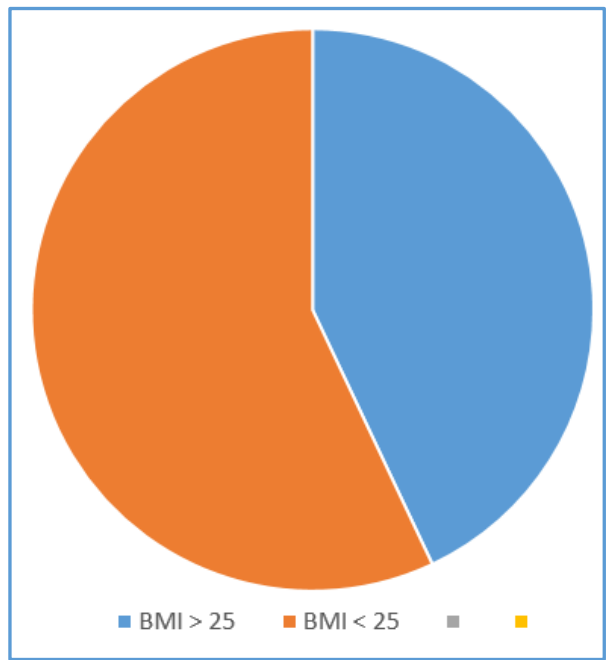

Figure 2. BMI Distribution

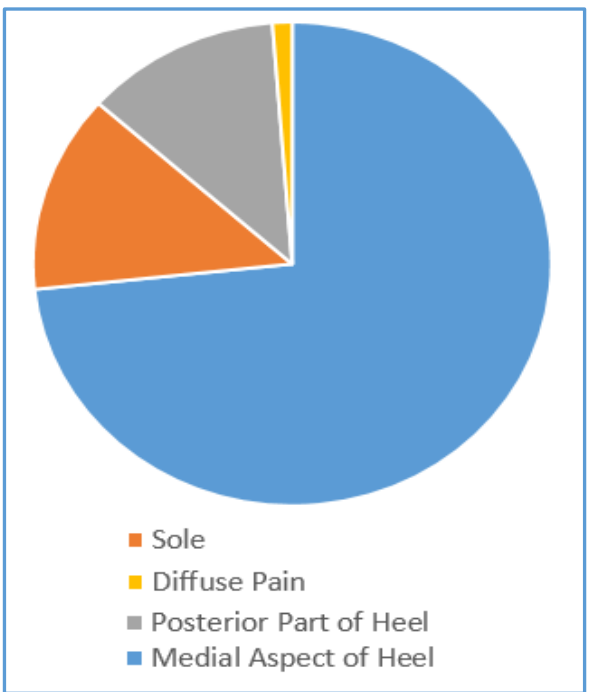

Figure 3. Site of Heel Pain

\begin{tabular}{|c|c|c|c|c|}
\hline \multirow{2}{*}{$\begin{array}{c}\text { BMI } \\
\text { Values }\end{array}$} & \multicolumn{2}{|c|}{ Number of Patients } & \multirow{2}{*}{ Total } & $\begin{array}{c}\text { Percentage } \\
(\%)\end{array}$ \\
\hline$<18.5$ & Male & Female & & 8 \\
\hline $18.5-24.99$ & 63 & 9 & 16 & 49 \\
\hline $25-29.99$ & 35 & 32 & 95 & 32 \\
\hline$>=30$ & 7 & 4 & 21 & 11 \\
\hline Total & 111 & 83 & 194 & 100 \\
\hline Table 1. Correlation of BMI, Sex Ratio and Heel Pain \\
\hline
\end{tabular}




\begin{tabular}{|c|c|c|}
\hline Age Group & Number of Patients with BMI > 25 & \% \\
\hline $0-9$ & 0 & 0 \\
\hline $10-19$ & 0 & 0 \\
\hline $20-29$ & 13 & 15.47 \\
\hline $30-39$ & 26 & 30.9 \\
\hline $40-49$ & 28 & 33.3 \\
\hline $50-59$ & 12 & 14.29 \\
\hline$>=60$ & 5 & 5.95 \\
\hline Total & 84 & 100 \\
\hline \multicolumn{3}{|c|}{ Table 2. Age Distribution } \\
\hline
\end{tabular}

\begin{tabular}{|c|c|}
\hline BMI & Heel Pain \\
\hline$<17.5$ & $0 \%$ \\
\hline $17.5-21$ & $7 \%$ \\
\hline $21-26$ & $33 \%$ \\
\hline $26-31$ & $31 \%$ \\
\hline $31-36$ & $18 \%$ \\
\hline$>36$ & $11 \%$ \\
\hline Total & $100 \%$ \\
\hline \multicolumn{2}{|c|}{ Table 3. BMI and Heel Pain by Heelspur.com 1998} \\
\hline
\end{tabular}

\section{DISCUSSION}

In 1835, Quetelet noted the body mass relationship to height in normal young adults was least affected by height when the ratio of weight-to-height squared was used rather than merely using the ratio of the weight-to-height or weight-toheight raised to the third power.[13]

In 1972, Keys et al[13] severely criticised the validity of Metropolitan Life Insurance published data,[14] which used weight for height for defining people who were underweight or overweight. They popularised the Quetelet Index in their population-based studies, which is also as the Body Mass Index (BMI). They suggested that by squaring the height, it reduces the contribution of leg length in the equation and tends to normalise the body mass distribution at each level of height, that is it reduces the effect of a variance in height in the relationship of weight-to-height. This was considered to be important, because most of the body fat is in the trunk. But, Keys et al also pointed out that even the BMI rather poorly represents a person's percent of body fat. Later, World Health Organization (WHO) classification of body weight for height based on the BMI was published[15] and it was widely adopted.[16]

Perry et al (1983) ${ }^{[17]}$ calculated that the impact load over the calcaneal tuberosity was about $5 \mathrm{~kg} / \mathrm{cm}^{2}$ with a repetition rate for walking of 1160 impacts per mile (721 per km). Such repetitive trauma on a less elastic heel pad could lead to inflammation and oedema. It seems possible that the increase in heel-pad thickness with age and increasing body weight leads to loss of the heel-pad elasticity and to liability to develop plantar heel pain.

In a survey by heelspur.com in 1997, they stated that the incidence of heel pain was $1 \%$ in the $1^{\text {st }}$ decade, $10 \%$ in $2^{\text {nd }}$ decade, $30 \%$ in $3^{\text {rd }}$ decade, $40 \%$ in $4^{\text {th }}$ decade, $15 \%$ in $5^{\text {th }}$ decade and $4 \%$ above the age of 59 years. Similar pattern could be appreciated in our study. The average age of the patients suffering from heel pain in our study is 39 years, which is comparable with the survey results of heelspur.com (2000), where they have found the average age of onset as 41 years.[18]

V Marwah (1983)[19] found $67.5 \%$ of his patients complaining of pain in the medial aspect of the heel, which was similar to our results of $72 \%$ heel pain in the same region.
Rano JA et al[7] used a questionnaire to obtain information in each of the patient groups and to determine characteristics of patients with plantar heel pain. They also took standard weight bearing lateral radiographs to determine overall foot structure. Their study depicted that the typical patient was female, had heel pain for just over 1 year with a sedentary-tomoderate activity level. Although, height was comparable, patients with heel pain had a higher BMI $(30.4+/-0.7)$ than those without heel pain $(28.2+/-0.7, \mathrm{p}=.04)$. They concluded that BMI played a greater role in heel pain than the foot structure, as they found no structural commonalities that would explain these patient's pain.

According to V Marwah[19] in his series of forty patients of idiopathic painful heel, he considered reduction of weight in obese patients as a treatment for heel pain of idiopathic origin.

JG Furey[20] in 1975 found $36.9 \%$ of his patients suffering from heel pain are obese. V Marwah[19] in 1983 found 50\% of his patients suffering from heel pain are thin built. $27.5 \%$ of the patients are obese and $22.5 \%$ are stocky. Somachi $\mathrm{P}^{[21]}$ (1994) found the average BMI of the patients suffering from heel pain was $26.24 \pm 3.42$. Rano et al[7] (2001) in study found patients with heel pain had a higher BMI $(30.4 \pm 4)$ than those without heel pain. Daniel et al[22] (2003) found $80 \%$ of his patients suffering from heel pain have BMI $>25$. He stated that an individual who spent majority of their workday on their feet and those whose BMI is $>30 \mathrm{~kg} / \mathrm{m}^{2}$ are at increased risk of developing plantar fasciitis.

KDB Van Leeuwen et al[23] reviewed 51 studies (1 prospective, 46 case-control and 4 cross-sectional studies), where he found that a higher Body Mass Index (BMI) (BMI>27) was consistent with clinical association between higher BMI and plantar fasciopathy.

A survey study by Heelspur.com in 1998 (Table 3) made the following observations on BMI and heel pain.[18] They concluded that $60 \%$ patients with heel pain were having a BMI of more than 26 , suggestive that overweight and obesity are related to heel pain.

In our study of 194 cases, we found $43 \%$ of the total cases of heel pain have BMI (Body Mass Index) of > 25, i.e. overweight patients. There are numerous reasons and risk factors for heel pain in adults and isolating a single factor implicating for the same is difficult. Here, in this study, the patients with heel pain are observed and all other causes or risk factors are tried to be excluded. Also, out of the 111 male patients 41 patients have BMI $>25$, comprising about $37 \%$ of the total male patients. Of the 83 female patients, 42 patients have BMI $>25$, comprising about $51 \%$ of the total female cases. Thus, a high BMI was found commonly in the female patients than the male patients with heel pain.

\section{CONCLUSION}

This is probably the first study of its kind in the NorthEastern Region of the country, which evaluated heel pain and BMI. However, a comparative study including the work pattern, foot structure and type of foot wear used by patients with a longer follow-up is required to find out whether high BMI might have a significant impact on heel pain.

\section{REFERENCES}

[1] Steill WF. Painfull heel. Practitioner 1922;108:345-6. 
[2] Lapidus PW, Guidotti FP. Painful heel: report of 323 patients with 364 painful heels. Clin Orthop Relat Res 1965;39:178-86.

[3] Jozsa LG, Kannus P. Human tendon: anatomy, physiology and pathology. Champaign, IL: Human Kinetics Publisher 1997.

[4] Jahss MH. Examination. In: Jahss MH, edr. Disorders of the foot. $1^{\text {st }}$ edn. Philadelphia: WB Saunders Company, 1982.

[5] Butterworth PA, Landorf KB, Smith SE, et al. The association between body mass index and musculoskeletal foot disorders: a systematic review. Obes Rev 2012;13(7):630-42.

[6] Menz HB, Barr EL, Brown WJ. Predictors and persistence of foot problems in women aged 70 years and over: a prospective study. Maturitas 2011;68(1):83-7.

[7] Rano JA, Fallat LM, Savoy-Moore RT. Correlation of heel pain with body mass index and other characteristics of heel pain. J Foot Ankle Surg 2001;40(6):351-6.

[8] Frey C, Zamora J. The effects of obesity on orthopaedic foot and ankle pathology. Foot \& Ankle Int 2007;28(9):996-9.

[9] Irving DB, Cook JL, Young MA, et al. Obesity and pronated foot type may increase the risk of chronic plantar heel pain: a matched case-control study. BMC Musculoskelet Disord 2007;8:41.

[10] Tanamas SK, Wluka AE, Berry P, et al. Relationship between obesity and foot pain and its association with fat mass, fat distribution, and muscle mass. Arthritis Care Res (Hoboken) 2012;64(2):262-8.

[11] Butterworth PA, Urquhart DM, Cicuttini FM, et al. Fat mass is a predictor of incident foot pain. Obesity (Silver Spring) 2013;21(9):E495-9.
[12] World Health Organization. Global database on body mass index: BMI classification http://apps.who.int/bmi/index.jsp?IntroPage=intro_3 .html

[13] Keys A, Fidanza F, Karvonen MJ, et al. Indices of relative weight and obesity. J Chron Dis 1972;25(6):329-43.

[14] Metropolitan Life Insurance Company. New weight standards for men and women. Stat Bull 1959;40:1-4.

[15] WHO. Physical Status: the use and interpretation of anthropometry: report of The World Health Organization (WHO) Expert Committee. Geneva, Switzerland: World Health Organization, 1995.

[16] Flegal KM, Carroll MD, Kuczmarski RJ, et al. Overweight and obesity in the United States: prevalence and trends, 1960-1994. Int J Obes Relat Metab Disord 1998;22(1):39-47.

[17] Perry J. Anatomy and biomechanics of the hind foot. Clin Orthop Relat Res 1983;177:9-15.

[18] Heelspur.com survey database: Year 2000 Survey - 2, 655 responses as of $10 / 1 / 2000$

[19] Marwah V. Painful heel: clinical and radiological basis. Ind J Bone Joint Surg 1982:16(1).

[20] Furey JG. Plantar fasciitis. The painful heel syndrome. J Bone Joint Surg Am 1975;57(5):672-3.

[21] Prichasuk S. The heel pad in plantar heel pain. J Bone Joint Surg Br 1994;76(1):140-2.

[22] Riddle DL, Pulisic M, Pidcoe P, et al. Risk factors for plantar fasciitis: a matched case control study. J Bone Joint Surg Am 2003;85-A(5):872-7.

[23] Van Leeuwen KDB, Rogers J, Winzenberg T, et al. Higher body mass index is associated with plantar fasciopathy/'plantar fasciitis': systematic review and meta-analysis of various clinical and imaging risk factors. $\mathrm{Br} \quad \mathrm{J}$ Sports Med 2015;0:1-12. doi:10.1136/bjsports-2015-094695. 